\title{
EVALUATION OF MASTICATORY MUSCLE ACTIVITY AND SURVIVAL RATE OF SINGLE IMPLANT-RETAINED MANDIBULAR OVERDENTURE FABRICATED FROM THERMOPLASTIC VERSUS CONVENTIONAL ACRYLIC RESIN. A RANDOMIZED CONTROLLED TRIAL
}

\author{
Wafaa I. Ibrahim* and Dina M. Elawady**
}

\begin{abstract}
Background: Electromyographic (EMG) activities of single implant-retained mandibular overdentures (MODs) has been dubious. Midline fracture of the denture is the most common complication related to Single implant-retained MODs. Thermoplastic polymethylmethacrylate (PMMA) acrylic resin achieves even distribution of forces and helps in absorption of impact forces which occurs during functional and parafunctional activities.
\end{abstract}

Aim of the study: This clinical study aimed to investigate whether thermoplastic PMMA can improve the EMG activity and decrease the incidence of denture fracture in single implant- retained MODs. Materials and Methods: A randomized controlled trial was designed, where 28 completely edentulous patients ( 15 male, 13 female) were enrolled and randomly divided into two equal groups. Group I (control group) received single implant- retained MOD fabricated from conventional PMMA and group II received a single implant- retained MOD fabricated from thermoplastic PMMA acrylic resin. Patients' muscle activity was evaluated at baseline and at 3,6 and 12 months using EMG. The survival rate of MOD was evaluated by recording the incidence of midline fractures. Results: There was a significant improvement in the EMG activity of the masseter and temporalis muscle of the thermoplastic PMMA group in all the follow-up periods. There was a non-statistically significant difference in the MOD survival between groups. However, the decrease in fracture incidence was clinically significant in the thermoplastic PMMA acrylic MOD group.

Conclusion: Within the limitation of this study, it was concluded that the fabrication of single implant-retained MODs from thermoplastic PMMA acrylic resins improves masticatory muscle activity and overdenture survival.

KEYWORDS: Masticatory muscle activity, single implant-retained mandibular overdenture, thermoplastic acrylic resin, conventional acrylic resin

* Lecturer, Department of Prosthodontics, Faculty of Oral and Dental Medicine, Delta University for Science and Technology, Egypt.

** Lecturer, Department of Removable Prosthodontics, Faculty of Dentistry, Modern Science and Arts University (MSA), Egypt. 


\section{INTRODUCTION}

The traditional management of completely edentulous patients with conventional complete dentures has developed many problems of discomfort, difficulty in chewing, pain, and retention. ${ }^{1}$ Introduction of dental implants helped to overcome many of these problems.

Rehabilitation of completely edentulous patients with implant-retained MODs; improves muscle activity, maximum biting force, chewing efficiency, and obviously increases patient satisfaction. ${ }^{2,3}$ When compared to conventional dentures; several studies found that implant-supported MODs showed improvement in EMG activity. ${ }^{4-6}$

Mandibular single implant-retained MODs have emerged as a treatment modality that addressed the limited financial resources of patients and simultaneously enabled the management of conventional complete denture problems. ${ }^{7-13}$

Clinical studies evaluating EMG activities of single implant- retained MODs are scarce and rare. Studies comparing single implant-retained MODs to conventional dentures reported that patients complaining from discomfort and functional difficulties with their conventional mandibular dentures, have shown a significant increase in the maximum bite force and improvement in the chewing ability when rehabilitated with single implant-retained MODs. ${ }^{6,14}$

However, a randomized controlled trial queried the masticatory muscle activity of the single implant-retained MODs when compared to two implant-retained MODs and reported that the twoimplant subjects presented a statistical significant improvement in EMG activity. ${ }^{15}$

Midline fracture of the denture is considered the most common complication associated with single implant-retained MOD. A high incidence of fracture of the acrylic resin denture base at the area of the implant may be explained by the fact that the single implant may act as a pivot and the MOD at the midline is usually thin. Many approaches have been introduced to overcome this problem. Reinforcement with metal mesh has been introduced as one of the solutions of this problem and was reported to be a reliable treatment option. 16,17 In 2007, a study by Gonada et al advocated the reinforcement of the single implant MOD to reduce the strain and prevent the MOD deformation and subsequent fracture. ${ }^{18}$

Retention, support and stability are three important factors which affect the masticatory function of dentures and their fracture resistance. One of the treatment alternatives that help in increasing denture retention, support and improve masticatory performance is the thermoplastic denture base materials. ${ }^{19}$

Flexible acrylic resin achieves even distribution of forces and reduces localized pressure. Besides, the flexible acrylic resin probably helps in absorption of impact forces which occurs during functional and parafunctional activities. ${ }^{20}$ Improved flexural and impact strength are claimed advantages of thermoplastic PMMMA. Moreover, flexible dentures are more esthetic and highly acceptable by the patients. ${ }^{21}$ It is characterized by dimensional stability, absence of porosity and improved denture adaptation..$^{22,23}$

Up to our knowledge, there are no previous studies comparing the EMG activity and overdenture survival in single implant-retained MOD with different denture base materials. This clinical study aimed to investigate whether thermoplastic PMMA can improve the EMG activity and decrease the incidence of denture base fracture in single implantretained MOD. The null hypothesis is that there is no significant difference in EMG activity and overdenture survival between conventional heat polymerized hard PMMA and thermoplastic PMMA. 


\section{MATERIALS AND METHODS}

A randomized controlled trial was designed, twenty eight completely edentulous patients (15 male, 13 female) were enrolled according to the inclusion and exclusion criteria from the Removable Prosthodontic clinic, Faculty of dentistry, MSA University.

\section{Sample size calculation:}

If the difference in the response of matched pairs is normally distributed with standard deviation 20 and the true difference in the mean of EMG activity is 20 . A total of 28 patients (14 in each group) was required to be able to reject the null hypothesis that the difference in response is zero with probability (power) of 0.8 and type I error probability is 0.05 .

Participants were assigned to two equal groups randomly. Patients of group I (control group) received single implant-retained MODs fabricated from heat-polymerized hard PMMA (Dentaplast Opti-Press TM bredent GmbH \& Co.KG, Senden, Germany). Group II received a single implant- retained MOD fabricated from thermoplastic PMMA (Polyan IC TM bredent GmbH \& Co.KG, Germany). Allocation concealment was performed using computer generated random number (RANDOM. ORG). Each participant selected a sealed opaque envelop that determined his/her number. Only single blinding was feasible (the assessor).

Inclusion criteria: completely edentulous patients of age range 55 to 70 were selected, medically and psychologically eligible patients for implants placement. Patients with adequate bone quality and quantity at midline and adequate interarch space detected clinically and radiographically.

Exclusion criteria: patients suffering from uncontrolled diabetes, osteoporosis, temporomandibular disorders, bleeding disorders or any medical condition that preclude implants placement were not enrolled. Patients taking chemotherapy or radiotherapy and heavy smokers were also excluded.
The study was approved by the Scientific Research Ethics Committee of MSA University. The participants signed an informed consent after being well-informed of the trial procedures.

\section{Presurgical preparation:}

New complete dentures were fabricated to be utilized during radiographic evaluation and to serve for temporization. The mandibular dentures were duplicated and gutta percha markers were inserted in the potential implant site (denture midline). Participants were scanned using CBCT (CBCT, i-CAT Vision $囚$; Imaging Sciences International) and blue sky Bio software (Blue Sky Plan® V3, Blue Sky Bio, LLC, USA) was used for implant planning.

The gutta percha markers were then removed and midline sleeve was made in the radiographic stent which was kept in $0.2 \%$ Chlorhexidine to be used as a surgical stent on the day of the surgery.

Preoperative antibiotics (1gm Augmentin ${ }^{\circledR}$, prednisone) and mouth washes $(0.2 \%$ chlorhexidine digluconate) were prescribed to the participants 2 hrs before surgery and continued for one week.

\section{Surgical procedures:}

For all patients, a standardized 2-stage submerged surgical protocol was implemented to place a single implant in the midline of the edentulous mandible. Small crestal incision was cut and a mucoperiosteal flap was reflected. Implant sites were indicated using the surgical template which was perfectly stabilized in place. Sequential drilling was performed under copious irrigation according to manufacturer instructions. Twenty eight implants of screw shaped, root form, self-tapping implants were placed in the midline for both groups (DENTIUM dental implant system, Korea). Implants were of the same length and diameter (12 mm X $4.1 \mathrm{~mm}$ )

During the osteointegration period, temporization was performed by relining and fitting of the 
previously fabricated dentures using a tissue conditioner (Temporary soft liner, Dentsply). A second stage surgery was performed eight weeks after to place the healing abutments, which were replaced with the locator attachments (Dentium system, Dentium Co. Kore) after two weeks.

\section{Prosthodontic procedures:}

Conventional upper complete denture and MOD were fabricated for group I using compression molding technique following the manufacturer instruction. ${ }^{24}$

For group II, a conventional upper complete denture was fabricated, and a thermoplastic PMMA MOD was fabricated using thermoplastic biocompatible "Polyan IC" (Polyan IC, Modified methacrylate, Bredent, Germany) processed by injectable molding technique (Thermopress 400 version 2.4/2.56, Bredent, Germany) following the manufacturer instruction (figure 1). ${ }^{25}$

\section{Direct pick up}

For both groups, white block-out spacers were slipped around the male part of the locator attachments (figure 2a). The black processing cap was fitted in the metal housing which was placed on the locator attachment's female part. The newly fabricated MODs of both groups were then modified to accommodate the locator attachments, midline sleeves were cut in the MODs opposite to the attachments.

Proper seating of the MODs and absence of any interference between the fitting surface of the MODs and locator attachments were verified by absence of rocking and perfect occlusion.

Chairside self-cure acrylic resin (Heraeus Kulzer $\mathrm{GmbH}$, Germany) was mixed and injected using a plastic syringe in the prepared sleeves. Patients were instructed to occlude on their dentures until complete polymerization of the acrylic resin. The MODs were then removed with the picked-up metal housing in their fitting surface (figure $2 b$ ). Finishing of the MODs was performed and the black processing cap was replaced with the red locator nylon cap (figure 2c).

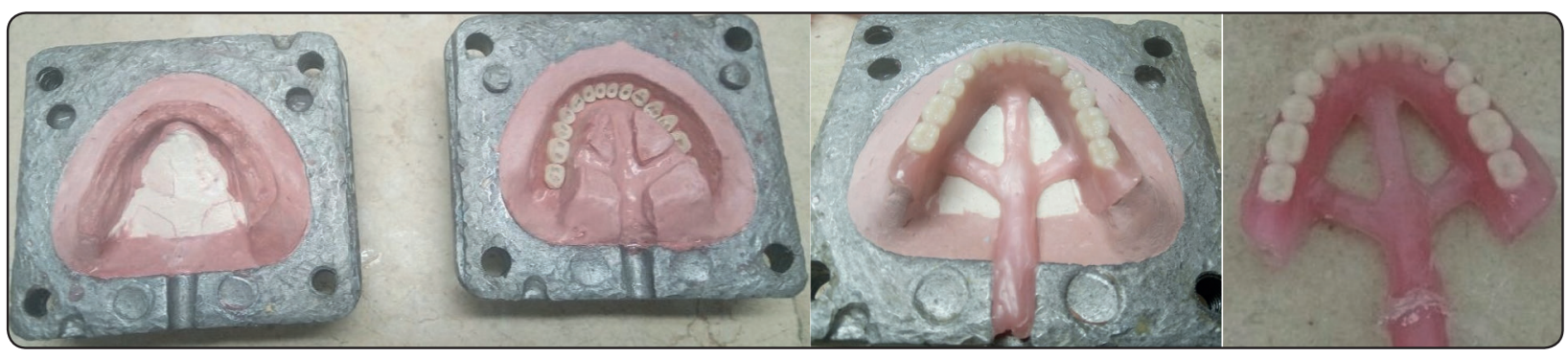

Fig. (1) MOD fabricated using injectable molding technique

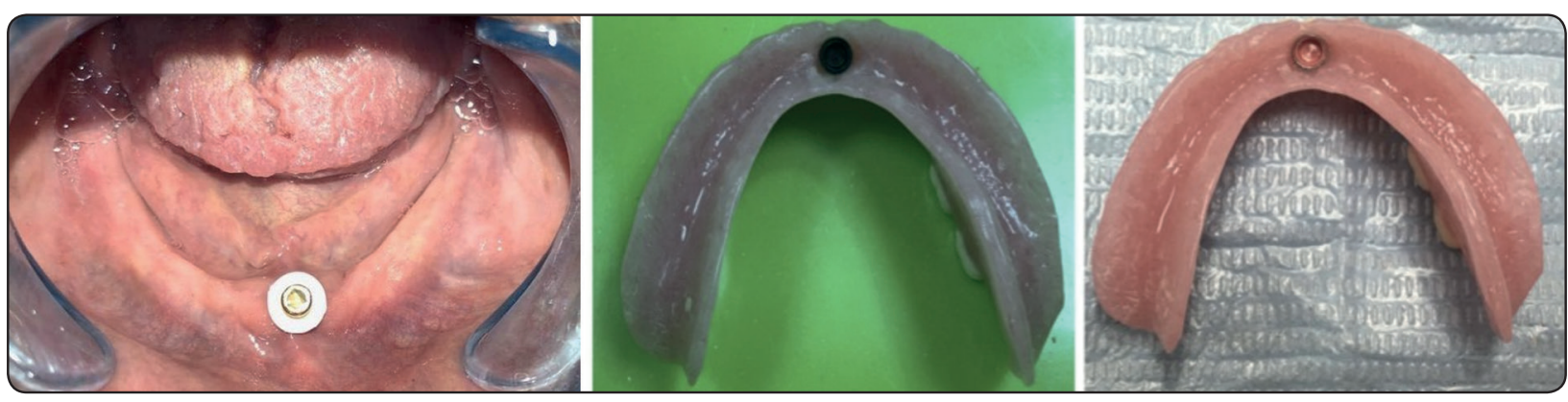

Fig (2) a) ite block-out spacers slipped around the male part of locator attachments b) picked-up metal housing. c) black processing cap replaced with red locator nylon cap 
Participants were trained on insertion and removal of their MODs and instructed to wear them for two weeks. After two weeks of implants loading, patients were recalled for electromyographic evaluation.

\section{Electromyographic evaluation}

Patients' muscle activity was evaluated at baseline (two weeks from new MOD insertion) using surface EMG during chewing hard and soft food. A clear plastic sheet was customized for each patient for precise reposition of the surface electrode in the successive patient recalls. The oral commissures and the outer canthus of the eye were taken as reference points for future relocating of the plastic sheet during reading intervals.

During the electromyographic evaluation, patients were instructed to maintain a comfortable erect position with their head unsupported and their hands resting on their thighs. The surface electrodes were positioned on the superficial masseter and anterior temporalis muscle (Figure 3a) and these positions were transferred to the clear template which was pierced at these points.

Alcohol swabs (70\% isopropyl alcohol) was used to clean their skin at the marked positions. The ground electrode (reference electrode) was filled with a conductive EEG paste (K-Ygel Ten 20 Weaver and Co. Aurora, U.S.A) on its inner sides and placed on the patients' forehead. Adhesive tape was used to fix the reference electrodes on the corresponding positions.

The right and left temporalis and masseter muscles' surface EMG activity was recorded during patients' chewing (figure 3b,3c). The total time of the experiment was 8 minutes, during which the patients chewed $1 \mathrm{~cm}$ of hard food (carrot) and 1 $\mathrm{cm}$ of soft food (banana) on each side. The food was placed on the first molar region of each chewing side. To decrease the influence of fatigue, a 1-minute interval was imposed between each evaluation.
For each type of food, the test was repeated 5 times with 2 minutes recovery rest period, then the mean was calculated and statistically analyzed. All EMG'S tests were performed for all patients by the same assessor and under the same environmental conditions. The technique used and the guidelines were previously explained to the patient.

\section{Survival rate of MODs}

The survival rate of MODs was evaluated by recording the incidence of mid-line fractures. A visible crack in the acrylic resin of the MOD or complete separation of its parts were considered as a fracture. Fractured dentures were identified in this study as not surviving. The survival rate of MODs (time to fracture) in each group throughout the 12 months follow up period was calculated and compared using Kaplan-Meier (alpha=.05) method and long-rank test.

\section{The statistical method}

Statistical description of data was in terms of mean \pm standard deviation $( \pm S D)$ and was tested for the normal assumption using Shapiro Wilk test. For independent samples, comparison between the studied groups was performed using Student $t$ test. Within group comparison between the different time points was done using repeated measures analysis of variance (ANOVA) test with multiple paired t test as posthoc multiple 2-group comparisons after applying Bonferroni adjustment of multiple comparisons. Survival analysis was done using Kaplan Maier statistics calculating the median survival time for each group and the corresponding survival graphs. Two-sided $P$ values was considered statistically significant if less than 0.05 . All statistical calculations were done using the computer program IBM SPSS (Statistical Package for the Social Science; IBM Corp, Armonk, NY, USA) release 22 for Microsoft Windows. 


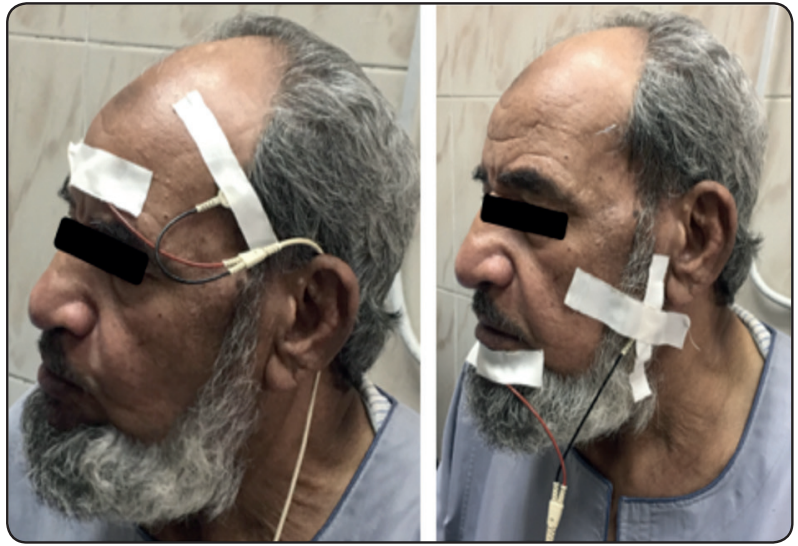

Fig. (3a) Surface electrode placed on the temporalis muscle and masseter muscle

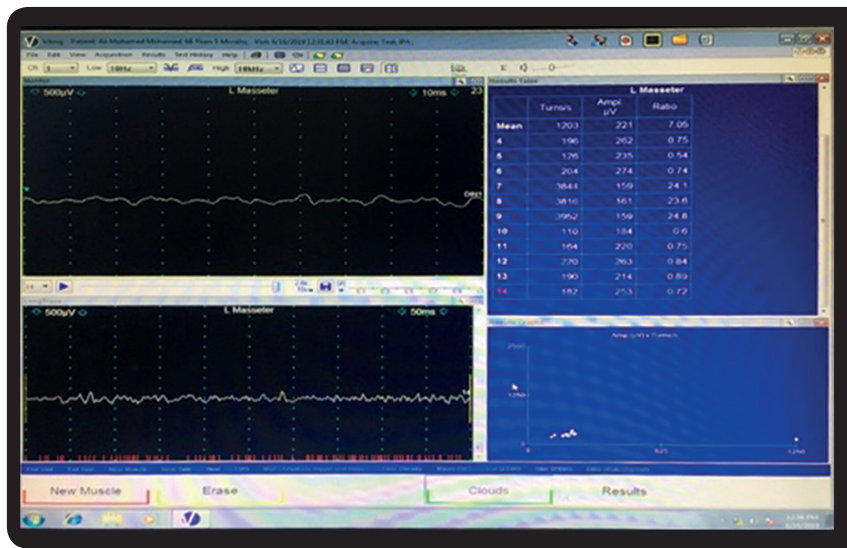

Fig. (3c) Surface EMG activity of the right and left masseter and temporalis muscles

\section{RESULTS}

Twenty eight patients were included in this study (15 male, 13 female), with age range 55 to 70 . All the included patients finished the 12 months followup period with no dropouts. There was no implant failure during the follow-up period, with a survival rate of $100 \%$.

\section{EMG activity}

\section{Comparison between the conventional hard PMMA and thermoplastic PMMA groups re- garding EMG activity}

The effect of different denture base materials on the EMG activity of the masseter and temporalis muscles is shown in table 1 and table 2 respectively.

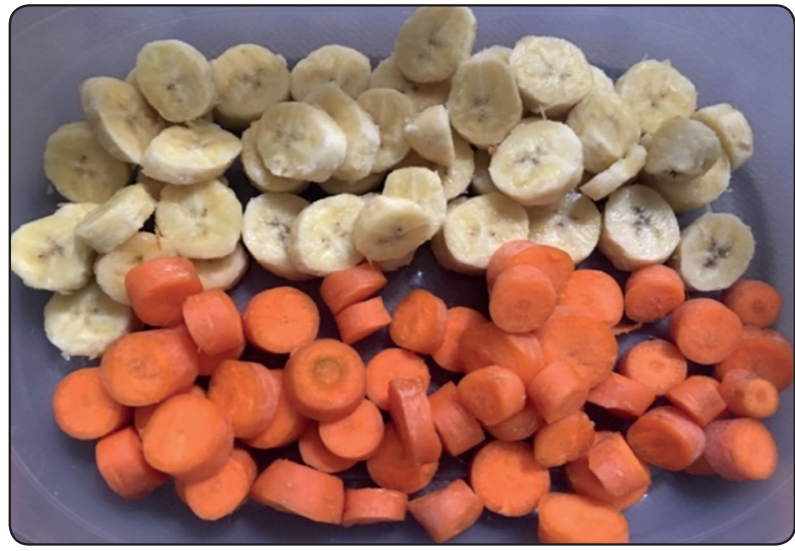

Fig. (3b) Patients chewed $1 \mathrm{~cm}$ of carrot then $1 \mathrm{~cm}$ of banana on each side.

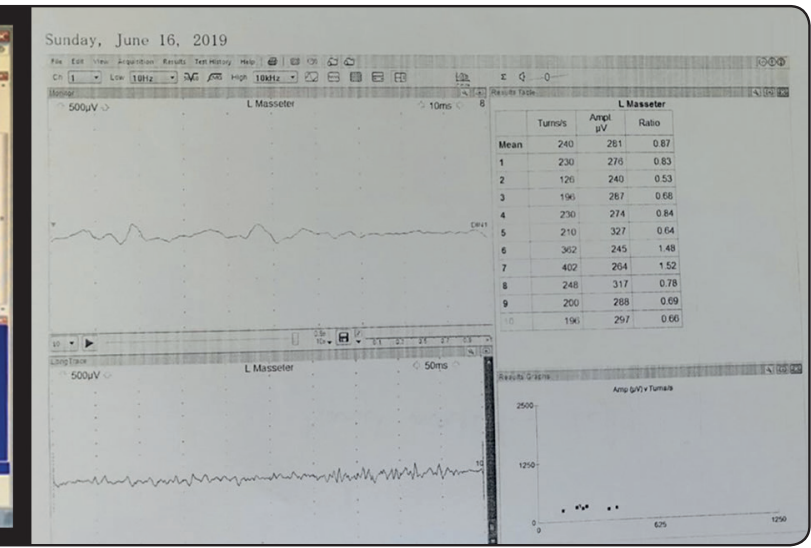

As shown in table 1; except for the baseline, a significant decrease (improvement) in the EMG activity of the masseter muscle was shown in the thermoplastic PMMA group when compared to conventional PMMA group at 3,6 and 12 months with P-value of $(0.002,0.011,0.001)$ respectively. Furthermore, the temporalis muscle EMG activity improved significantly in the thermoplastic group over the follow-up period with P-value of 0.004 at 3 months and $<0.001$ at 6 and 12 months.

\section{Effect of time on muscle activity}

The effect of time on the EMG activity of masseter and temporalis muscles throughout different follow-up periods in the conventional hard PMMA and thermoplastic PMMA groups is shown 
in figure 4 , table 1 and table 2 .

As shown in figure $4 \mathrm{a}$ and table 1 , there is a significant decrease in EMG activity of the masseter muscle over the study time points with $\mathrm{P}<0.001$. Additionally, there is a significant decrease in EMG activity of temporalis muscle with $\mathrm{P}<0.001$ as shown in figure $4 b$ and table 2.

\section{Survival rate of overdenture}

The effect of different denture base materials on the survival rate of the MOD is shown in figure 5

A non-statistically significant difference was found in the overdenture survival in the thermoplastic PMMA group when compared to conventional hard PMMA group in all the follow-up periods $(\mathrm{P}=0.1)$

TABLE (1) Comparison of EMG results between the 2 groups over the study time points in Masseter muscle

\begin{tabular}{|c|c|c|c|c|c|}
\hline \multirow[t]{2}{*}{ Item } & \multicolumn{2}{|c|}{$\begin{array}{c}\text { Conventional PMMA } \\
(\mathrm{n}=14)\end{array}$} & \multicolumn{2}{|c|}{$\begin{array}{c}\text { Thermoplastic PMMA } \\
(\mathrm{n}=14)\end{array}$} & \multirow[t]{2}{*}{$p$ value } \\
\hline & Mean & SD & Mean & SD & \\
\hline Base line & $150.29^{\mathrm{a}}$ & 8.37 & $150.93^{\mathrm{a}}$ & 9.52 & 0.852 \\
\hline 3 months & $129.54^{b}$ & 11.31 & $116.24^{b}$ & 8.42 & $0.002^{*}$ \\
\hline 6 months & $117.49^{c}$ & 10.25 & $105.92^{\mathrm{c}}$ & 11.97 & $0.011^{*}$ \\
\hline 12 months & $114.65^{\mathrm{d}}$ & 11.21 & $99.86^{d}$ & 9.21 & $0.001^{*}$ \\
\hline $\mathrm{p}$ value & \multicolumn{2}{|c|}{$<0.00^{1 *}$} & \multicolumn{2}{|c|}{$<0.001^{*}$} & \\
\hline
\end{tabular}

* statistically significant

$a, b, c, d:$ different letters means statistically significant difference in pairwise comparisons

TABLE (2) Comparison of EMG results between the 2 groups over the study time points in Temporalis muscle

\begin{tabular}{|c|c|c|c|c|c|}
\hline \multirow[t]{2}{*}{ Item } & \multicolumn{2}{|c|}{$\begin{array}{c}\text { Conventional PMMA } \\
(\mathrm{n}=14)\end{array}$} & \multicolumn{2}{|c|}{$\begin{array}{l}\text { Thermoplastic PMMA } \\
(\mathrm{n}=14)\end{array}$} & \multirow[t]{2}{*}{ P value } \\
\hline & Mean & SD & Mean & SD & \\
\hline Base line & $142.72^{\mathrm{a}}$ & 12.43 & $144.51^{\mathrm{a}}$ & 11.83 & 0.699 \\
\hline 3 months & $122.53^{b}$ & 9.76 & $111.95^{\mathrm{b}}$ & 7.92 & $0.004^{*}$ \\
\hline 6 months & $117.79^{c}$ & 10.53 & $96.91^{\mathrm{c}}$ & 6.82 & $<0.001^{*}$ \\
\hline 12 months & $109.11^{\mathrm{d}}$ & 8.29 & $88.96^{d}$ & 7.56 & $<0.001^{*}$ \\
\hline $\mathrm{p}$ value & \multicolumn{2}{|c|}{$<0.001^{*}$} & \multicolumn{2}{|c|}{$<0.001^{*}$} & \\
\hline
\end{tabular}

* statistically significant

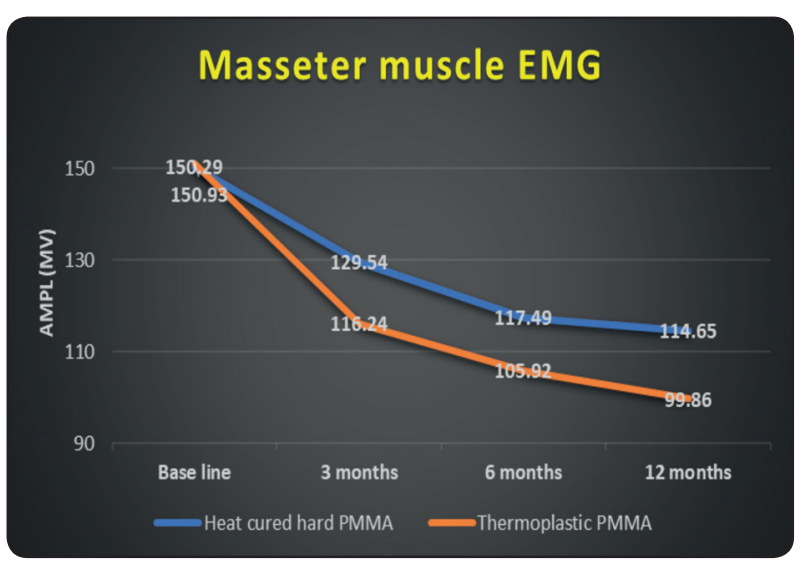

Fig 4 a) Line graph showing the effect of time on the masseter muscle activity of heat cured hard PMMA and thermoplastic PMMA

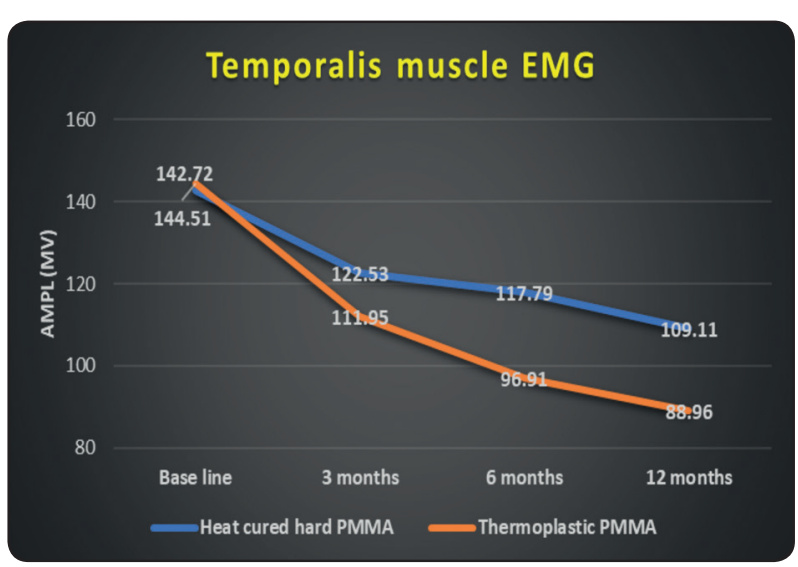

Fig. 4 b) Line graph showing the effect of time on the temporalis muscle activity of heat cured hard PMMA and thermoplastic PMMA 


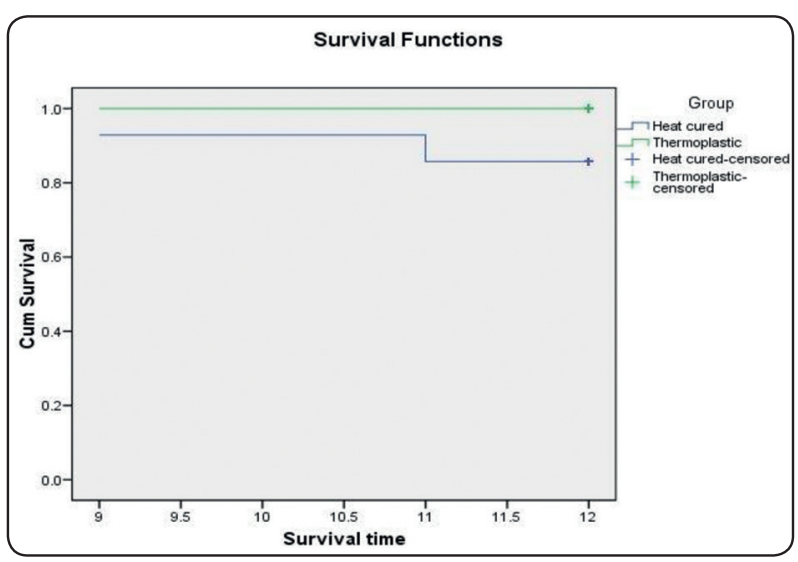

Fig. (5) Kaplan-Meier analysis

\section{DISCUSSION}

The purpose of this randomized clinical trial was to compare the masticatory muscle activity and the survival of single implant-retained MODs fabricated from two different denture base material; either conventional hard PMMA or thermoplastic PMMA acrylic resins.

Surface electromyography was used to evaluate muscular activity as it showed a great efficiency in the analysis of muscle activity in implant-retained dentures. ${ }^{26,27}$ The choice of surface electrodes was for several reasons, as they are considered less painful than needle electrodes which can change the records of the EMG activity. In addition, they help in the assessment of a larger area of muscles. ${ }^{28}$

Masseter and temporalis muscles were selected to denote the activity of the muscles of mastication as they are the strongest and largest muscles of mastication and they play an important role in mandibular movements. ${ }^{29}$ A higher EMG activity of the masseter muscle was shown in the results of our present study when compared to the temporalis muscle. This can be due to anatomical and functional differences between both muscles. Furthermore, this can be attributed to the fact that during chewing, the masseter muscle exerts greater effect on the prosthesis than the temporalis muscle. ${ }^{30}$
Blinding of the subjects or the care provider was not possible due to the obvious difference between the two types of MODs. However, an independent assessor who was not aware of the intervention type, assessed the electromyographic activity of the masseter and temporalis muscles.

Patients rehabilitation with single implant -retained MOD fabricated from thermoplastic PMMA showed an improvement in muscle activity. Therefore, the null hypothesis that there is no significant difference in EMG activity between the conventional hard PMMA and thermoplastic PMMA acrylic MOD was rejected. The findings of our study showed that there is a significant improvement in muscle activity of thermoplastic PMMA acrylic resin group when compared to conventional hard PMMA acrylic resin group. Additionally, there was a gradual improvement in the mean EMG activity of masseter and temporalis muscles in both groups at 3,6 , and 12 months follow-up periods.

These results are in agreement with a previous study comparing conventional hard PMMA with flexible MODs retained by two implants. It was stated that chewing with flexible MODs resulted in faster and fewer chewing strokes which improves the masticatory activity and preserves the masticatory system. There was an improvement in muscle activity of implant MODs fabricated from flexible acrylic resin, and they proposed it's use as an alternative treatment option for implants MOD patients. ${ }^{31}$

The gradual improvement in the mean EMG activity can be due to the adaptation of the neuromuscular system to the implant-retained MOD and hence the masticatory effort decreases with time. ${ }^{32}$ Previous studies revealed that rehabilitation of edentulous patients with implant-supported MODs aided in better neuromuscular coordination by improving stability, support and retention of the denture. Accordingly, the masticatory muscles are directed towards the masticatory function 
instead of controlling and stabilizing the denture during function..$^{33,34}$ This can be explained from a neurologic perspective, as less electric activity is used by the muscle to do the same function.

The null hypothesis of comparing the fracture incidence of single implant - retained mandibular MOD fabricated from conventional hard PMMA versus thermoplastic PMMA acrylic resin was not rejected, as a non-statistically significant difference was revealed in the fracture incidence of the two groups.

Despite the statistically insignificant difference in overdenture survival between the two groups reported in this study, a clinically significant decrease in fracture incidence was recognized in the thermoplastic PMMA acrylic MOD group, it is relevant to mention that two MODs fractured in the conventional MOD group with no fractures in thermoplastic MOD group. The higher flexural and impact strength as well as the better adaptation of thermoplastic PMMA acrylic resin may explain this result ${ }^{20-23}$

The results of this study agree with a study reported that the denture base affect the load applied to implant and act as important factor for MOD survival rate. Close adaptation of the denture base reduces the movement of the denture and allow the forces distribution over the implants and supporting structure in turn decrease the stress concentration around the implants. ${ }^{35-37}$ Therefore, the clinically significant decrease in fracture incidence in the thermoplastic PMMA acrylic MOD group may also be attributed to the low strain in peri-implant area, low stress in the abutments and absence of damaging strain concentration around the only implant achieved by the thermoplastic PMMA acrylic resin.

In this study, the Polyan IC was selected to use as a material for fabrication of denture bases processed by injection molding technique. It is a thermoplastic resin biocompatible, colour stable and residual monomer content $<1 \%$ so no mucosal irritation Moreover, this thermoplastic can be relined and repaired easily. ${ }^{38}$

Gharechahi et al. compared the dimensional accuracy of acrylic resin denture bases processed using conventional molding technique to those fabricated using injection molding technique. They assumed that, injection molding technique revealed higher dimensional precision when compared to the conventional molding technique, leading to higher denture base adaptation. ${ }^{39}$

It was claimed that the combination of polymerization shrinkage and distortion of denture bases due to thermal stresses which occur in compression molding technique affects the adaptation accuracy of denture base to the underlying tissues creating a microgap. Injection molding technique is an alternative technique which may overcome these problems and increase denture base adaptation..$^{40,41}$

Besides the type of prosthesis which is an implant-tissues supported overdenture that distributes the load between the residual ridge and the implant, this prosthesis has the ability to protect the implants by using locator attachments which act as stress breakers. Additionally, it had been claimed that lateral loads have more deleterious effect on dental implants than vertical loads. The low profile height of locator attachments had decreased the lateral load on the MOD. Lastly, it should be observed that the opposing arch was restored with upper complete denture that applies less forces on opposite arch in comparison to natural dentition or fixed restorations.

The non-significant difference may also be attributed to a decreased number of events and the number of patients included in the study. More randomized clinical trials with longer follow up periods and bigger sample size are recommended to provide an evidence based conclusion. 


\section{CONCLUSION}

Within the limitation of this study, it was concluded that thermoplastic PMMA denture base processed by using injectable mold may ensure well fitted denture base and subsequently improved masticatory muscle activity and decreased fracture incidence compared to PMMA hard denture base processed by conventional method, when single implant- retained mandibular MOD are used.

\section{ACKNOWLEDGEMENT}

The authors would like to acknowledge Prof. Eman Ahmed Maher, Professor in Clinical Neurophysiology unit, Faculty of Medicine, Cairo University for her unlimited help with the assessment of electromyographic activity for the study population

\section{REFERENCES}

1. Tatematsu M, Mori T, Kawaguchi T, Takeuchi K, Hattori M, Morita I, et al. Masticatory performance in 80-year-old individuals. Gerodontology 2004; 21:112-119.

2. Boven GC, Raghoebar GM, Vissink A, Meijer HJ. Improving masticatory performance, bite force, nutritional state and patient's satisfaction with implant MODs: A systematic review of the literature. J Oral Rehabil 2015; 42:220-233.

3. Ibrahim WI, Ragheb NA. Prosthetic complications and patient satisfaction of bar versus locator-retained overdentures in completely edentulous patients. A randomized clinical trial. Research \& Reviews: Journal of Dental Sciences 2019;7:1-8.

4. Karkazis H. EMG activity of the masseter muscle in implant supported MOD wearers during chewing of hard and Soft food. J Oral Rehabil 2002;29:986-991.

5. Van Kampen F, van der Bilt A, Cune MS, Bosman F. The influence of various attachment types in mandibular implant-retained MODs on maximum bite force and EMG. J Dent Res 2002; 81:170-173.

6. Elsyad MA, Hegazy SA, Hammouda NI, Al-Tonbary GY, Habib AA. Chewing efficiency and electromyographic activity of masseter muscle with three designs of implantsupported mandibular MODs. A cross-over study. Clin Oral Implants Res 2014;25:742-748.
7. Tavakolizadeh S, Vafaee F, Khoshhal M, Ebrahimzadeh Z. Comparison of marginal bone loss and patient satisfaction in single and double-implant assisted mandibular MOD by immediate loading. J Adv Prosthodont 2015;7:191-199

8. Bryant S, Walton J, MacEntee M. A 5-y Randomized Trial to Compare 1 or 2 Implants for Implant MODs. J Dent Res 2015;94:36-43.

9. Kronstrom M, Davis B, Loney R, Gerrow J, Hollender L. A prospective randomized study on the immediate loading of mandibular MODs supported by one or two implants; a 3-year follow-up report. Clin Implant Dent Relat Res 2014;16:323-329.

10. Harder S, Wolfart S, Egert C, Kern M. Three-year clinical outcome of single implant-retained mandibular overdentures - results of preliminary prospective study. Journal of dentistry. 201;39:656-61.

11. Elawady DM, Kaddah AF, Omar H, Abdelnaby N. Impact of single versus two implants on the bone height loss and bone density for patients restored by implant-retained mandibular overdentures. RCT. Egypt dent j 2016; 62:1-8

12. Elawady DM, Kaddah AF. Single vs 2 implants on periimplant marginal bone level and implant failures in mandibular implant overdentures: a systematic review with meta-analysis. Journal of Evidence Based Dental Practice 2017;17:216-25.

13. Elawady DM, Kaddah AF, Ahmed Yaseen Alquaibi AY, Osman RB. The influence of implant number on peri-implant marginal bone level and implant failures in mandibular implant overdentures. A systematic review with metaanalysis. Int. J. of Adv. Res. 5 (Jul). 1326-1334] (ISSN 2320-5407).

14. Bilhan H, Geckili O, Mumcu E, Cilingir A, Bozdag E. The influence of implant number and attachment type on maximum bite force of mandibular overdentures: a retrospective study. Gerodontology. 2012;29:e116-20.

15. Alqutaibi AY, Kaddah AF, Farouk M. Randomized study on the effect of single-implant versus two-implant retained overdentures on implant loss and muscle activity: a 12-month follow-up report. Int J Oral Maxillofac Surg. 2017;46:789-97.

16. Grageda E, Rieck B. Metal-reinforced single implant mandibular overdenture retained by an attachment: a clinical report. J Prosthet Dent. 2014;111:16-9.

17. Nischal K, Chowdhary R. Early Loaded Single Implant Reinforced Mandibular Overdenture. Case reports in dentistry 2016;2016:4213753. 
18. Gonda T, Ikebe K, Dong J, Nokubi T. Effect of reinforcement on overdenture strain. Journal of dental research. 2007;86:667-71.

19. Mohamed GF. Clinical evaluation of the efficacy of soft acrylic denture compared to conventional one when restoring severely resorbed edentulous ridge. Cairo Dent J 2008; 24:313-323.

20. Sunitha NS, Jagadeesh KN, Kalavathi SD, Kashinath KR. 'Flexible dentures' - an alternate for rigid dentures?. Journal of Dental Sciences \& Research 2010;1:74-9.

21. Agrawal B, Mishra SK, Mangal A. Insight in to complete esthetics with flexible denture. Guident. 2018;11:8-10

22. Tandon R, Gupta S, Agarwal SK. Denture base materials: from past to future. Ind J Dent Sci. 2010; 2:33-9.

23. Negrutiu M, Sinescu C, Romanu M, Pop D, Lakatos S. Thermoplastic resins for flexible framework removable partial dentures. Timisoara M J. 2005; 55:295-99.

24. Winkler S (ed). Essentials of complete denture prosthodontics. Year Book Medical Pub, 1988.

25. Hamanaka I, Takahashi Y, Shimizu H. Mechanical properties of injection-molded thermoplastic denture base resins. Acta Odontologica Scandinavica. 2011;69:75-9.

26. Van Der Bilt A, Van Kampen FM, Cune MS. Masticatory function with mandibular implant-supported overdentures fitted with different attachment types. European Journal of Oral Sciences 2006;114:191-6.

27. Bersani E, Regalo SC, Siéssere S, Santos CM, Chimello DT, De Oliveira RH, Semprini M. Implant - supported prosthesis following Brånemark protocol on electromyography of masticatory muscles. Journal of oral rehabilitation. 2011;38:668-73.

28. Quach GH. Surface electromyography: Use, design and technical overview. Introduction to biomedical engineering. Concordia University. 2007; 17-8.

29. Wheeler RC. Dental anatomy, physiology and occlusion $7^{\text {th }}$ ed. W.B. Saunders Co. Philadelphia and London. 1993; 393-8.

30. Uçankale M, Akoğlu B, Özkan Y, Ozkan YK. The effect of different attachment systems with implant-retained overdentures on maximum bite force and EMG. Gerodontology 2012;29:24-9.

31. Ibraheem EM, Nassani MZ. The effect of flexible acrylic resin on masticatory muscle activity in implant-supported mandibular overdentures: a controlled clinical trial. Electron Physician 2016;8:1752-1758.

32. .Radwan W. Correlation between biting force and muscular activity in mandibular single implant supported MOD with and without attachment. Saudi Dent J. 2012; 24: 43-8.

33. Tiwari P, Karambelkar V, Patel J, Sethuraman R. The comparative evaluation of the masticatory efficiency of root supported attachment retained MOD and implant supported MOD by EMG. An in vitro study, J Dent Med Sci. 2015; 14: 78- 93.

34. Santos C, Vitti M, Matsumoto W, Berro R, Semprini M, Hallak J, Regalo S. Using MODs on implants and complete denture. Effect on postural maintenance of masticatory musculature. Braz J Oral Sci. 2008; 7: 1550-4.

35. Palmqvist S, Sondell K, Swartz B. Implant supported maxillary overdentures outcome in planned and emergency cases. Int J Oral Maxillofac Implant 1994:9;184-190

36. Shamnur SN, Jagadeesh KN, Kalavathi SD, Kashinath KR. Flexible dentures- An alternate for rigid dentures? J Dent Sci Res. 2005; 1:74-9

37. Ichikawa T, Horiuchi M, Wigianto R, Matsumoto N, in vitro study of mandibular implant retained overdentures the influence of stud attachment on load transfer to the implant and soft tissue. Int J Prosthodontic 1996;9:394-399

38. Senden KG, Shade W. Latest press release. Bredent $\mathrm{Gr}$ 2013;49:22-4.

39. Gharechahi J, Asadzadeh N, Shahabian F, Gharechahi M. Dimensional changes of acrylic resin denture bases: conventional versus injection-molding technique. J Dent (Tehran) 2014;11:398-405

40. Lee C, Bok S, Bae J. Comparative adaptation accuracy of acrylic denture bases evaluated by two different methods. Dent Mater J 2010;29:411

41. Shawky Y, Youssef H. Adaptation accuracy and retention of injection - and compression - molded maxillary complete denture: in - vitro and in - vivo study. Egypt Dent $\mathrm{J}$ 2014; 1011-7. 